\title{
EFFECTS OF HYDROTHERMAL UNREST ON STRESS AND DEFORMATION: INSIGHTS FROM NUMERICAL MODELING AND APPLICATION TO VULCANO ISLAND (ITALY)
}

Gilda Currenti ${ }^{1}$, Rosalba Napoli ${ }^{1}$, Armando Coco $^{2}$, Emanuela Privitera ${ }^{1}$

'Istituto Nazionale di Geofisica e Vulcanologia, Sezione di Catania - Italy

${ }^{2}$ Department of Mechanical Engineering and Mathematical Sciences, Oxford Brookes University - United Kingdom

\section{Abstract}

A numerical approach is proposed to evaluate stress and deformation fields induced by hydrothermal fluid circulation and its influence on volcano-flank stability. The numerical computations have been focused on a conceptual model of Vulcano Island, where geophysical, geochemical and seismic signals have experienced several episodes of remarkable changes likely linked to the hydrothermal activity. We design a range of numerical models of hydrothermal unrest and computed the associated deformation and stress field arising from rock-fluid interaction processes related to the thermo-poroelastic response of the medium. The effects of model parameters on deformation and flank stability are explored considering different multilayered crustal structures constrained by seismic tomography and stratigraphy investigations. Our findings highlight the significant role of model parameters on the response of the hydrothermal system and, consequently, on the amplitudes and the timescale of stress and strain fields. Even if no claim is made that the model strictly applies to the crisis episodes at Vulcano, the numerical results are in general agreement with the pattern of monitoring observations, characterized by an enhancing of gas emission and seismic activity without significant ground deformation. The conceptual model points to a pressurization and heating of the shallow hydrothermal system $(1-0.25$ $\mathrm{km} \mathrm{bsl)} \mathrm{fed} \mathrm{by} \mathrm{fluid} \mathrm{of} \mathrm{magmatic} \mathrm{origin.} \mathrm{However,} \mathrm{for} \mathrm{the} \mathrm{assumed} \mathrm{values} \mathrm{of} \mathrm{model}$ material and source parameters (rate of injection, fluid composition and temperature) the pressure and temperature changes do not affect significantly the flank stability, which is mainly controlled by the gravitational force.

Key words: Hydrothermal circulation; Numerical modeling; Thermo-poro-elasticity; Volcano flank instability; Vulcano Island 


\section{Introduction}

Active volcanoes grow and build up so rapidly that their edifices are inherently unstable and their flanks are usually displaced under the actions of different agents. While volcano instability has been recognized and documented at many volcanoes worldwide, the cause-and-effect relationships among the involved processes have so far been difficult to capture. The volcano dynamics plays an active role in the factors controlling volcano deformation and structural stability, and numerous processes such as magma intrusions (McGuire, 1996; Iverson, 1995; Elsworth and Voigth, 1996; Elsworth and Day, 1999; Voight and Elsworth, 1997), replenishment of fresh magma in reservoirs and seismic activity (Voight et al., 1981) can trigger volcanic flank failure. Among the others, also hydrothermal fluid circulations due to thermal expansion and pore pressure acting on rocks may significantly alter the stress state of the volcanic edifice (Rinaldi et al., 2010; Bonafede, 1990, 1991; De Natale et al., 1991, 2001; Hurwitz et al., 2007; Hutnak et al., 2009; Orsi et al., 1999; Hayba and Ingebritsen, 1994) and hydrothermal alteration often plays a major part in increasing susceptibility to failure. However, up to date few studies have addressed the quantification of expected deformation and stress variations caused by hydrothermal fluids during a generic unrest period (Reid, 2004). To afford this topic, we implemented a hydro-mechanical model to evaluate stress, strain and deformation fields caused by hydrothermal fluid circulation.

The hydro-mechanical model is implemented by coupling a thermo-poroelastic numerical code, developed under COMSOL software (Comsol, 2012), with TOUGH2, a commercial software simulating multi-phase and multi-component fluid flow and heat transfer. Based on thermo-poroelasticity theory and the definition of a failure criterion, stress and strain fields are evaluated to define the regions of the volcano edifice more likely to displace and fail. Numerical results show the contribution of hydrothermal fluid flow circulation associated with induced thermoelastic and porepressure changes, providing a quantitative estimate for deformation and failure of a volcano edifice.

The model is applied to the case-study of Vulcano Island, an active volcanic complex which is potentially affected by significant geohazards related to the activity of the magmatic and hydrothermal systems. In 1988, indeed, fracturing and increase of the hydrothermal activity resulted in an enhanced slope instability and caused part of the 
small tsunami (Achilli et al., 1998; Tinti et al., 1999). A correlation between the gravitational instability of the slope and the increased volcanic activity was suggested as the direct cause of the slide (Tinti et al., 1999). However, other processes such as water-rock interaction and repetition of inflation-deflation cycles, which could lower the rock shear strength of the volcanic edifice, were not ruled out (Rasà and Villari, 1991). In recent times, no magmatic eruptions have taken place at the island, but recurrent thermal and seismic crises, attributed to magma-water interaction (Federico et al., 2010; Alparone et al., 2010), each lasting no more than a few months, have occurred. These crises are accompanied by sudden and intense changes in the set of geophysical and geochemical monitored parameters. These evidences are a signature of the significant interplay between rock and fluid circulation within the hydrothermal system. Therefore, the estimate of the rock-fluid interaction processes and their influences on volcano-flank stability are of primary importance for the Vulcano Island hazard assessment. Here, we investigate the role played by fluid injection, composition, and medium rheology in controlling the internal stress state of the volcano, whose amplitudes and distributions outline the volcano edifice regions that are more likely to fail. As most parts of the system are inaccessible to direct observations, the exploration of different scenarios by means of numerical simulations will help in understanding and characterizing the hydrothermal system activity and in interpreting the associated geophysical observations.

\section{Geological setting}

Vulcano is the southernmost island of a NW-SE elongated submarine volcanic ridge which rises more than $1 \mathrm{~km}$ from the continental slope (Romagnoli et al., 2013). The ridge develops along two main systems of NW-SE trending right-lateral strike-slip faults, parallel to the NW-SE Tindari-Letojanni system, which extends up to NE Sicily (De Astis et al., 2013; De Ritis et al., 2005). The Vulcano structural pattern is generally dominated by a NNW-SSE trend, representing a surficial expression of the Tindari-Letojanni system, and by minor N-S to NE-SW trending normal faults and cracks associated to the main NW-SE shear zone (Ventura et al., 1999). The subaerial morphology of the island is characterized by: (i) two main overlapping

101 structural depressions more than $2.5 \mathrm{~km}$ wide, named the Piano caldera and La 102 Fossa caldera; (ii) La Fossa cone, a 390 m high composite edifice, located within the 
central sector of La Fossa caldera, and (iii) the pyroclastic edifice of Vulcanello,

104 which with its lava platform form a roughly circular peninsula on the northern tip of the island (Chiarabba et al., 2004; Revil et al., 2008).

106 Since the 70s, several geophysical studies were executed to detect and define the shallow structures of the volcano complex (lacobucci, 1977; Barberi et al., 1994;

108 Blanco-Montenegro et al., 2007; Napoli and Currenti, 2016). Moreover, valuable

109 information on the subsurface structure of the La Fossa caldera were obtained, by 110 two deep geothermal drillings (Fig.1) in 1983-1987 (Giocanda and Sbrana, 1991), 111 located at the foot of the south-western and northern flanks of La Fossa cone. The 112 former encountered a shallow monzodioritic intrusion at about $1350 \mathrm{~m}$ bsl, and 113 reached a vertical depth of $2050 \mathrm{~m}$ where a temperature of $419 \mathrm{C}^{\circ}$ was founded. The 114 second well found a temperature of $243^{\circ} \mathrm{C}$ at $1338 \mathrm{~m}$ and between 350 and $400^{\circ} \mathrm{C}$ at $1151578 \mathrm{~m}$ (Faraone et al. 1986).

116 Since 1890, when the last eruption of La Fossa cone occurred, the volcano activity 117 has been characterized by recurrent thermal and seismic crises due to magma-water 118 interaction (Federico et al., 2010; Alparone et al., 2010). Gravity, seismological and 119 geochemical studies (Berrino 2000; Chiodini et al., 1992; Alparone et al., 2010) 120 detected an active hydrothermal system beneath La Fossa caldera, between 500 and $1211500 \mathrm{~m} \mathrm{bsl}$, whose activity is represented by the intense fumarolic emissions in the 122 summit area. In particular, a few high temperature $\left(400{ }^{\circ} \mathrm{C}\right)$ zones are active (De 123 Astis et al., 2003) within the crater, while on the southern and northern flanks of the 124 edifice, temperatures generally do not exceed $98^{\circ} \mathrm{C}$ (Barde-Cabusson et al., 2009).

125 Fumaroles temperature and the superficial manifestations strongly increase when 126 input of fluids of magmatic origin occurs even without evidence of magmatic rising, as 127 happened in 2004-2006. In these cases the anomalous degassing episodes could 128 derive from changes in rock permeability (Todesco, 1997) or reflect a pulsating 129 degassing process from a deep pressurized stationary magma body (Granieri et al., 130 2006).

\section{3. Hydro-mechanical model}

133 The hydro-mechanical model is based on the governing equations of the thermo134 poro-elasticity theory, which describes the response of a porous medium to the 135 propagation of hot fluid. A one-way coupling model is here considered in which the 
pore pressure and temperature changes influence the elastic stresses, but not viceversa. Although it is a limitation of the model, this assumption is not so restrictive since uncoupled and coupled pore pressure solutions are quite close for many ranges of medium properties (Roeloffs, 1988).

\section{Fluid flow model}

142 The hot fluid circulation in the hydrothermal system is simulated using the EOS2 module of TOUGH2 software (Pruess et al., 1999), which incorporates $\mathrm{CO}_{2}-\mathrm{H}_{2} \mathrm{O}$ equations of state in the temperature and pressure range $0-350{ }^{\circ} \mathrm{C}$ and $0-100 \mathrm{MPa}$, respectively. It solves the mass and energy balance equations for a multiphase ground-water flow (Pruess et al., 1999). The mass balance equations can be resumed as follows:

$$
\frac{\partial Q^{m}}{\partial t} q \nabla \cdot \boldsymbol{F}^{m}-q^{m}=0
$$

where. is the accumulation term, $\boldsymbol{F}$ the flux and $q$ the source (or sink) term and $m$ the mass component (water or $\mathrm{CO}_{2}$ ). A full list of the symbols with their unit of measurements is provided in Table 1. The accumulation term for mass balance equation is described by . ${ }^{m}=0 \sum_{2} 1_{2} 3_{2} \chi_{2}^{m}$, where the subscript $\gamma$ refers to the liquid Flmor gas Fgmphase, respectively, 0 is the porosity, $1_{2}$ the density, $3_{2}$ the saturation and $\chi_{2}^{m}$ the mass fraction of component $m$ present in phase $\gamma$. The fluid flux $\boldsymbol{F}^{m}=$ $\sum_{2} \chi_{2}^{m} \boldsymbol{F}_{2}$ is described by the Darcy's law extended to two-phase conditions with separate equations for the gas and liquid phases:

$$
\boldsymbol{F}_{2}=\mathbf{v}_{2} 1_{2}=\frac{k k_{r \gamma} \rho_{\gamma}}{\mu_{\gamma}}\left(\nabla P_{2}-1_{2} \widehat{\boldsymbol{g}}\right)
$$

where $\mathbf{v}_{2}$ is the Darcy's velocity, $k$ and $k_{r 2}$ are the absolute and relative permeability to phase $\gamma$, respectively, $\mu_{2}$ the viscosity, $P_{2}$ the fluid pressure, and $\widehat{g}$ the gravitational acceleration vector.

The energy balance equation is represented by (1) as well (with the subscript $m=E$ standing for energy), where the accumulation and the flux terms are, respectively, . ${ }^{E}=0 \sum_{2} 1_{2} e_{2} 3_{2} q(1-0) 1_{R} C_{R} T$ and $\boldsymbol{F}^{E}=-\lambda_{r} \nabla T q \sum_{2} h_{2} \boldsymbol{F}_{2}$, where $e_{2}$ is the specific internal energy of the phase $\gamma, 1_{R}$ and $C_{R}$ are the density and the specific 
168 heat of the rock, respectively, $T$ is the temperature, $\lambda_{r}$ the thermal conductivity of the rock, and $h_{2}$ the specific enthalpy of the phase $\gamma$.

170 Each phase may be at a different pressure $P_{2}$ due to interfacial curvature and capillary forces. The difference between the gas and liquid pressures is referred as capillary pressure $P_{c}$. In order to close the equation system, relationships for the capillary pressure and relative permeabilities are needed. These relationships are usually posed as a function of the liquid saturation $3_{l}$, on the basis of experimental data. Therefore, the fluid flow process is also controlled by capillary pressure saturation - relative permeability relationships. TOUGH2 allows for investigating several hydrological models. One of the most common formulations used in hydrological models to describe these relationships is the Brooks-Corey function (Brooks and Corey, 1964) based on experimental observations and defined as:

$$
P_{c}=\frac{P_{b}}{S_{e}^{1 / \delta}}, \quad \text { with } \quad 3_{e}=\frac{S_{l}-S_{l r}}{1-S_{l r}}
$$

where $3_{e}$ denotes the effective liquid saturation, $3_{l r}$ the residual liquid saturation, $P_{b}$ the bubbling pressure and $\delta$ the pore size distribution index. The bubbling pressure, which is also called the displacement pressure, is the extrapolated capillary pressure at full liquid saturation. Brooks and Corey exploited the Burdine theory to derive the relative permeability-saturation relationships for gas and liquid phases:

$$
k_{r l}=3^{\frac{2+3 \delta}{\delta}}
$$

$$
k_{r g}=\left(1-3_{e}\right)^{2} \boldsymbol{F} 1-3^{\frac{2+\delta}{\delta}} m
$$

The parameters for the Brooks-Corey two-phase characteristic curves are fixed to average values of $3_{l r}=0.3, \delta=2$ and $P_{b}=5000 \mathrm{~Pa}$.

\section{Elasto-mechanical model}

Assuming that the timescale of deformation is slow enough to allow for pressure equilibration, the rock is in quasi-static equilibrium and the displacement can be found by solving the stress equilibrium equations coupled with thermo-poroelastic extension of the Hooke's law (Jaeger and Cook, 2007; Fung, 1965), giving the following set of equations: 


$$
\nabla \cdot \boldsymbol{\sigma}=\mathbf{H}
$$

$$
\boldsymbol{\sigma}=\lambda \operatorname{tr}(\boldsymbol{\varepsilon}) \mathbf{I}+2 G \boldsymbol{\varepsilon}+\alpha_{T} K \Delta T \mathbf{I}+\beta \Delta P \mathbf{I}
$$

$$
\boldsymbol{\varepsilon}=\frac{1}{2}\left(\nabla \mathbf{u}+(\nabla \mathbf{u})^{T}\right)
$$

201 where $\boldsymbol{\sigma}$ and $\varepsilon$ are the stress and strain tensors, respectively, $H$ is the body force, $\mathbf{u}$ is 202 the deformation vector and $\lambda$ and $G$ are the Lame's elastic medium parameters, 203 related to the Poisson ratio and Young's modulus. To the elastic stress tensor of the general Hooke's law, two terms are added: (i) the $\Delta P$ pore-pressure contribution from poroelasticity theory through the $\beta=\left(1-K / K_{s}\right)$ Biot-Willis coefficient and (ii) the $\Delta T$ temperature contribution from thermo-elasticity theory through the volumetric thermal expansion coefficient $\alpha_{T}$.

208 Within this framework the stress field inside the volcanic edifice originates from two main contributions (Iverson and Reid, 1992; Reid, 2004; Marti and Geyer, 2009; Zang and Stephansson, 2010; Muller et al., 2001): (1) the background stress composed of the gravitational loading and (2) the stress field generated by the pore pressure and thermo-elastic effect. Gravitational loading is included in the model by

213 imposing on each element an internal body force per unit volume $\boldsymbol{H}=-1_{R} \widehat{\boldsymbol{g}} z$, where

$2141_{R}$ is the density of the host rock, $\widehat{g}$ is the gravitational acceleration vector and $z$ the 215 elevation. The gravitational body force is included in the simulations to obtain an 216 overburden stress of rock at any given depth in the medium. The volcanic edifice 217 itself, acting as a load on the upper crust, generates a stress regime (Liu and 218 Zoback, 1992; Pan et al., 1995; Pinel and Jaupart, 2004; Currenti and Williams, 219 2014) that affects the flank stability (Reid, 2004). The mathematical problem is closed 220 by imposing zero displacements at infinity and stress-free boundary condition $\boldsymbol{\sigma} \cdot \mathbf{n}_{\mathbf{s}}$ $221=0$ on the ground surface, where $\mathbf{n}_{\mathbf{s}}$ is the normal vector to the ground surface. The problem is solved by finite element method using COMSOL Multiphysics (COMSOL, 2012). The pore-pressure and temperature contributions are fed from the outputs of 224 the TOUGH2 fluid flow model solutions by implementing a MATLAB script to automate the COMSOL computations at each time steps. 
Failure criteria

228 Assuming that the subsurface comprises poroelastic media, the mechanical response is governed by its effective stress distribution, which is the total stress modified by fluid pressure as follows:

232 where $\sigma$ is the total applied stress on the rock-fluid mixture and $P$ is the pore fluid pressure (Ranalli, 1995). The pore pressure acts against the total stress, effectively

234 reducing the resistance to failure. Several yield criteria have been investigated to model the mechanical behavior of rocks undergoing failure (Fung, 1965; Ranalli, 1995; Jaeger et al., 2007). Such failure depends on both the deviatoric stress and the overburden stress through the friction coefficient. The Drucker-Prager failure law can be properly used for modeling brittle behavior in the upper crust (Cattin et al., 2005;

239 Cianetti et al., 2012; Apuani et al., 2013; Got et al., 2013). The yield function for

240 Drucker-Prager failure in the case of no hardening (perfect plasticity) may be written 241 as:

$242 \quad Y_{f}=-\eta_{1} q \eta_{2} I_{1} q \sqrt{\mathrm{t}_{2}}$

243 where $I_{1}$ is the first invariant of the effective stress, $J_{2}$ the second invariant of the 244 deviatoric stress tensor, $\eta_{1}$ and $\eta_{2}$ medium coefficients. Generally, when the effective 245 stress state satisfies the yield criterion $Y_{f} \geq 0$, the material will undergo failure. The 246 Drucker-Prager criterion represents a smoothed version of the Mohr-Coulomb 247 frictional failure criterion for a three-dimensional case. Indeed, the coefficients $\eta_{1}$ and $248 \eta_{2}$ may be related to the Mohr-Coulomb frictional failure properties cohesion $(c)$ and 249 friction angle $(\theta)$, derived from laboratory experiments (Jaeger et al., 2007; Chen, 250 1982):

$251 \quad \eta_{1}=\frac{w c \cos \theta}{\sqrt{3} F 3-\sin \theta m} \quad \eta_{2}=\frac{2 \sin \theta}{\sqrt{3} F_{3}-\sin \theta m}$

253 The Drucker-Prager criterion, such as the Mohr-Coulomb one, accounts for the 254 experimental observations that yield stress of most rocks increases with increasing 255 mean normal stress (Jaeger et al., 2007; Mazzini et al., 2009; Liu et al., 2004). The 256 volume, where the condition in Eq. 7 is satisfied, delineates shear-failure potential at 257 any point within the volcano edifice and thus assists in pinpointing locations that have 258 an increasing exposure to flank failure. 


\section{4. Numerical Simulations}

261 In order to investigate the effect of temperature and pore pressure changes on flank 262 instability at Vulcano Island, it is necessary to outline a reasonable thermal and 263 mechanical regime existing in the shallowest crust of the volcanic edifice, in 264 agreement with geochemical and geophysical evidences. Firstly, TOUGH2 is run to 265 evaluate pressure and temperature variations with respect to their initial distributions, 266 which, then, are fed into the thermo-poroelastic solver to compute the deformation 267 and stress fields. Without losing of generality, the model is designed in an axi268 symmetric formulation in a computational domain of $10 \times 1.5 \mathrm{~km}^{2}$ which describes the 269 shallowest portion of the hydrothermal system (Fig. 2). We included the real 270 topography of Vulcano using a digital elevation model from the $90 \mathrm{~m}$ Shuttle Radar 271 Topography Mission (SRTM) data and a bathymetry model from the GEBCO 272 database (http://www.gebco.net/). The profile runs from the center of La Fossa cone 273 toward North-East in order to describe the average slope of the Vulcano Island in the 274 area affected by the 1988 landslide (Fig. 1). The domain was discretized in the radial 275 direction by a set of logarithmically spaced nodes with a horizontal resolution starting 276 from $20 \mathrm{~m}$ along the axis of symmetry and decreasing to $470 \mathrm{~m}$ at the external 277 boundary. Vertically, the domain was divided into 90 equally spaced layers, which 278 corresponds to a resolution of $20 \mathrm{~m} / \mathrm{layer}$. This discretization leads to about 10000 279 grid cells. In the thermo-poroelastic model the computational domain is bounded by 280 infinite mapped elements and meshed into 152859 isoparametric and arbitrarily 281 distorted triangular elements connected by 26090 nodes. The infinite mapped 282 elements use appropriate transformation functions to map the finite domain into an 283 infinite one and, hence, to make the displacements and stress fields vanish toward 284 infinity (Zienkiewicz et al., 1983). Due to the different grids adopted in the fluid-flow 285 and thermo-poroelastic solvers, pore pressure and temperature solutions are 286 interpolated from the TOUGH2 grid to the thermo-poroelastic solver nodes (Fig. 2).

\section{Fluid flow parameter}

289 Fluid flow simulations require the definition of boundary conditions, hydrological 290 medium properties and initial conditions. 
291 As for boundary conditions, primary variables of TOUGH2/EOS2 (pressure, 292 temperature and $\mathrm{CO}_{2}$ partial pressure; Pruess et al., 1999) are fixed at the top 293 surface for the entire simulation. In particular, atmospheric pressure is fixed along the 294 subaerial boundary and hydrostatic pressure is assigned to the submarine boundary. 295 Atmospheric values of temperature and $\mathrm{CO}_{2}$ partial pressure are also assigned 296 (Todesco et al., 2003). In the faraway side boundaries hydrostatic pressure and 297 geothermal gradient $\left(130{ }^{\circ} \mathrm{C} / \mathrm{km}\right.$; AGIP, 1987) are assigned, whereas the bottom 298 boundary has a constant basal heat flux of $60 \mathrm{~mW} / \mathrm{m}^{2}$ to represent heat flow from depth (Okubo and Kanda, 2010) and is impermeable except at locations where fluids are being injected.

301 The hydrological properties of the medium strongly control the response of the 302 hydrothermal system to the applied sources of fluids and boundary conditions and, 303 hence, affect the amplitude and the temporal evolution of the physical variables (pore pressure, temperature, gas saturation, stress-strain field and deformation). This is a relevant aspect, as hydrological properties may change significantly with rock type and chemical-physical condition and, consequently, a careful definition of in situ rock properties would be necessary. Unluckily, at Vulcano Island, site-specific values are poorly known. In order to define the hydrological model properties, we exploited the stratigraphy inferred from logs of the deep VP1 borehole (Fig. 1), which allows to identify the succession of different layers from top to bottom (Gioncada and Sbrana, 1991; Tommasi et al., 2016). We grouped the lithology units into two main classes distinguished, on average, by characteristic high (hyaloclastites, pyroclastites, scories) and low (latitic lava flows, trachytic intrusion) permeabilities. The complex

314 structure of the volcanic edifice is, therefore, simplified by a stratified model (A) consisting of two alternating layers with low (Layer 1) and high (Layer 2) porosity and permeability values (Fig. 3). In order to account for alteration along and across the main flow paths of hydrothermal fluids, a second model (B) is also investigated. It includes a $250 \mathrm{~m}$ wide inner zone, simulating the central pathway, with high porosity and permeability, and transition zones between the central pathway and the remaining domain, which extend for $250 \mathrm{~m}$ and have intermediate hydrological parameters (Table 2; Fig. 3). Porosity values, determined from laboratory test on rock samples from a $100 \mathrm{~m}$ deep borehole BL1 located near the VP1 borehole (Fig. 1), are scattered in the range between 0.1 and 0.4 (Tommasi et al., 2016). In the lack of 324 in-situ measurements, the values of permeability are set up on the basis of estimates 
325 in other similar volcanic environments (Todesco et al. 2010, Okubo and Kanda, 2011;

326 Rinaldi et al., 2011; Troiano et al., 2011; Coco et al., 2016).

327 The initial conditions of the numerical simulations are designed on the basis of a 328 conceptual model derived from geochemical investigations, which hypothesizes the 329 presence of a hydrothermal system at a depth of $0.5-1.5 \mathrm{~km}$ bsl with equilibrium 330 temperature up to $400^{\circ} \mathrm{C}$ (Federico et al., 2010). It is fed by fluids of magmatic origin, 331 and unrest events are ascribed to periods of increased fluid injections. Fluxes of 332 chemical components have been estimated from compositional analysis of the discharged fumaroles. Carbon dioxide represents the main constituent of anhydrous 334 gases discharged from the summit areas through plumes and crater fumaroles 335 (Inguaggiato et al., 2012). Over the past 15 years of observations, the $\mathrm{CO}_{2} / \mathrm{H}_{2} \mathrm{O}$ 336 weight ratio has varied from 0.05 to 0.5 , with an average value of approximately 0.23 . 337 Such large variations were interpreted as due to variable mixing of the magmatic 338 fluids, rich in $\mathrm{CO}_{2}$, with a shallower hydrothermal component (Chiodini et al. 1992; 1996). A water flux of about $1300 \mathrm{t} /$ day and a total $\mathrm{CO}_{2}$ output of $482 \mathrm{t} /$ day have been estimated for the whole area of Vulcano Island considering discharged fluids from crater fumaroles, soil degassing over the island, and bubbling and dissolved gas

342 (Inguaggiato et al., 2012). These estimates refer to periods of moderate hydrothermal activity. On the basis of these evidences, the model is run for thousands of years to reproduce a fluid state (pressure, temperature and gas saturation), which resembles the conceptual model of the hydrothermal system. Quasi-steady state conditions are reached by simulating a continuous injection of $1300 \mathrm{t} /$ day of pure water and 450 $\mathrm{t} /$ day of $\mathrm{CO}_{2}$ at a temperature of $350{ }^{\circ} \mathrm{C}$ for both model $\mathrm{A}$ and $\mathrm{B}$. The fluid is injected in a $250 \mathrm{~m}$ wide inlet located at the bottom of the domain near the symmetry axis. The pressure, temperature and gas saturation distributions are shown in Figs. 4a-c. In the model A, after reaching a quasi-steady state solution, a high-temperature deep zone develops above the fluid injection area extending horizontally up to $0.5 \mathrm{~km}$ of distance from the symmetry axis (Fig. 4a). In such a volume, the rock temperature reaches more than $300{ }^{\circ} \mathrm{C}$, and the highest value of gas saturation is reached (Fig. 4c). A gas-saturated zone is observed at the inlet, and saturation decreases in the shallow layers. Temperatures are distributed in a larger area up to the ground surface where values greater than $100{ }^{\circ} \mathrm{C}$ still appear. Pressure mainly follows the hydrostatic condition with perturbation concentrated within $500 \mathrm{~m}$ (Fig. 4b). Also in 358 the model B (Figs. 4d-f), a high-temperature deep zone develops above the fluid 
injection area but it affects a smaller volume extending horizontally up to $0.25 \mathrm{~km}$ of

360 distance from the symmetry axis. In such a volume, the temperature reaches more than $300^{\circ} \mathrm{C}$, and even if it gradually decreases in the shallow layers, values greater than $100{ }^{\circ} \mathrm{C}$ still appear just below the ground surface (Fig. 4d). Remarkable differences are observed in the temperature and gas saturation distributions with respect to model $A$. In model $B$ the higher permeability in the inner and transition zones favours the flow within these regions, which, consequently, are more heated. A gas-saturated area develops just below the ground surface and spreads up horizontally in the shallowest permeable layer (Fig. 4f).

\section{Mechanical parameters}

370

371

A heterogeneous medium for the subsurface structure of Vulcano Island is considered using a piecewise linear depth dependent distribution of the elastic material properties derived from seismic tomography (Chiarabba et al., 2004; Ventura et al., 1999). Within the computational domain the P-wave seismic velocity $V_{p}$ varies from $2 \mathrm{~km} / \mathrm{s}$ to $4 \mathrm{~km} / \mathrm{s}$ and the rock density $\rho$ ranges between $2100 \mathrm{~kg} / \mathrm{m}^{3}$ to $2400 \mathrm{~kg} / \mathrm{m}^{3}$ (Table 3). Low values of $V_{p}$ and $\rho$, related to the pyroclastics, hyaloclastites and hydrothermally altered rocks, were assigned to the shallow part of the volcanic edifice, up to $1 \mathrm{~km}$ of depth. Because of the axis-symmetric formulation, horizontal heterogeneities and local effects of high velocity bodies ( $V_{p}$ greater than 3 $\mathrm{km} / \mathrm{s}$ ) were disregarded. With increasing depth, higher values of seismic velocity and rock density related to intrusive or sub-intrusive bodies, as well as to crystallized conduits system, were assigned to the medium (Chiarabba et al., 2004). These $V_{p}$ and $\rho$ values were used to define the elastic Young modulus by the following equation (Kearey and Brooks, 1991):

$$
\mathrm{E}=\mathrm{V}_{\mathrm{p}}^{2} \rho_{R} \frac{(1-2 v)(1+v)}{1-v}
$$

An average value of 0.3 for the Poisson's ratio $v$ was used. Under these assumptions, within the computational domain the Young modulus increases from 9.0 GPa in the shallow layer to $23.3 \mathrm{GPa}$ at the bottom of the domain.

On the basis of literature data (Coco et al., 2016; Rinaldi et al., 2010; Todesco et al.,2010; Troiano et al., 2011), we chose average values for the volumetric thermal 
391 expansion parameter $\alpha_{T}$, fixed to $10^{-5}{ }^{\circ} \mathrm{C}^{-1}$, and for the drained bulk modulus, set to 5 392 GPa.

393 Estimates of the mechanical characteristics of rock masses are also required to 394 evaluate the Drucker-Prager failure criterion. Generally, in a geothermal volcanic 395 area such as Vulcano Island, built up by a stack of pyroclastics, tuffs, hyaloclastites 396 and hydrothermally altered clasts (De Astis et al., 2013), low friction angle and 397 cohesion are expected. Mechanical parameters of Vulcano rocks have rarely been 398 measured. Recently, a geotechnical characterization of cores collected from the BL1 399 borehole and of rock samples from Punte Nere deposits was conducted to estimate 400 their mechanical properties (Tommasi et al., 2016). The laboratory tests have 401 evidenced that hydrothermal alteration around fumaroles has changed mineralogy, 402 texture and mechanical behavior of the material. In particular, a reduction of friction 403 angle down to $26^{\circ}$ or $21^{\circ}$ was reported. Based on the results of laboratory test, 404 cohesion values from 0.5 to $1 \mathrm{MPa}$ were investigated for the parameters of the ideal 405 elastoplastic rheological model.

\section{Results}

408 Since the last eruption occurred during 1888-1890, the active volcanic center of La 409 Fossa cone displays fumarole activity, characterized by periodic phases of increased 410 output flux and temperatures of emitted fluids (Alparone et al., 2010; Federico et al., 411 2010). Enhanced fluid discharge from the crater fumaroles is supposed to be 412 sustained by an enhanced deep fluid injection, as experimentally supported by higher $413 \mathrm{CO}_{2} / \mathrm{H}_{2} \mathrm{O}$ ratios measured in high-temperature fumaroles during unrest (Granieri et 414 al., 2006; Paonita et al., 2013). In order to evaluate the effect of enhanced fluid 415 injection in the volcano-hydrothermal system on the deformation and stress fields, we 416 simulated an unrest phase of 1 year by increasing (after reaching the steady-state 417 solution) the flux rate to $2000 \mathrm{t} /$ day for the water and to $1000 \mathrm{t} /$ day for the carbon 418 dioxide content, in agreement with geochemical data collected at Vulcano Island 419 during unrest phase (Chiodini et al., 1996; Granieri et al., 2006). The distributions of 420 saturation and pressure and temperature changes at the end of the unrest, with 421 respect to the steady-state initial conditions, are displayed in Fig. 5. In the model A, 422 temperature and pore pressure changes do not propagate farther than $1 \mathrm{~km}$ from the 423 source region (Fig. 5a, b). The pressure changes reach $2 \mathrm{MPa}$ in correspondence of 
424 the fluid inlet, while the maximum temperature changes of about $10^{\circ} \mathrm{C}$ are 425 concentrated at its edge. Only slight temperature changes within $0.2^{\circ} \mathrm{C}$ are observed 426 near the ground surface. A gas saturated area is concentrated at the fluid inlet and 427 the saturation value suddenly drops below 0.5 at a depth of about $1.25 \mathrm{~km}$ bsl 428 extending up to the ground surface (Fig. 5c) with a similar pattern to that produced in 429 the steady-state conditions (Fig. 4c). In the model B, the fluid easily propagates 430 upward and the flow is mainly confined in the inner and transition zones where the 431 rock permeability is higher. The heated region extends up to the sea level showing 432 the maximum values at the depth of about $1 \mathrm{~km}$ bsl in correspondence of the edge of 433 the inlet area (Fig. 5d). The main pressure variations of about $0.5 \mathrm{MPa}$ are 434 concentrated within the inner region between $1 \mathrm{~km}$ and $0.25 \mathrm{~km}$ bsl (Fig. 5e). The 435 gas saturation distribution preserves the pattern produced in the steady-state 436 conditions, with a gas-saturated area just below the ground surface, and another area with high values of saturation grows in the deeper part near the symmetry axis between $1.5 \mathrm{~km}$ and $1 \mathrm{~km}$ bsl (Fig. 5f).

\section{Ground displacements}

441 Using the pressure and temperature solutions achieved from the fluid flow simulations, the evolution of ground deformation is then evaluated using the thermoporoelastic solver. In the model $\mathrm{A}$, after 1 year of continuous injection the radial 444 distribution of horizontal deformation reaches a maximum amplitude of about $0.4 \mathrm{~cm}$ at $1.25 \mathrm{~km}$ away from the symmetry axis, where the volcano edifice submerges. Concurrently, the vertical uplift attains about $0.5 \mathrm{~cm}$ from the origin $(r=0)$ to $1.25 \mathrm{~km}$ and diminishes to $0.1 \mathrm{~cm}$ within $2.5 \mathrm{~km}$ (Fig. 6). Remarkable differences are observed in the model $B$, where the radial distribution of horizontal deformation shows the maximum amplitude value of about $0.8 \mathrm{~cm}$ from $0.5 \mathrm{~km}$ to $1.5 \mathrm{~km}$ and then decreases within $4.5 \mathrm{~km}$. Simultaneously, the vertical uplift attains about $2.2 \mathrm{~cm}$ at the origin and vanishes to $0.1 \mathrm{~cm}$ within $2.5 \mathrm{~km}$ (Fig.6). The discrepancies between model $A$ and $B$ are attributable to the different distributions of pressure and temperature changes (Fig. 5). In model A these changes affect a wider area (Fig.5 a,b) and, in turn, reflect in a more extensive deformation pattern. Conversely, in model $B$ the temperature and pressure changes (Fig. $5 d, e$ ) are more confined in the inner zone because of the higher permeability of this region and, hence, they 
engender a narrower deformation pattern. The evolution of the vertical ground displacement arising from the simulated unrest was calculated at the ground surface at the origin point (Fig. 7). The vertical deformation in the summit area evolves almost linearly in time for the model A. Uplift begins as soon as the injection rate is increased and reaches the maximum amplitude of about $0.5 \mathrm{~cm}$ at the end of the unrest. In the model $B$, the evolution of the vertical uplift follows a non-linear trend. After an initial constant linear increase, the rate of deformation decays from 0.3 to 0.6 years, when it starts to rise again. The rise of deformation rate after 0.6 years in model $B$ is due to the concurrent onset of the upward migration of the pore pressure changes, which primarily contribute to the deformation with respect to thermo-elastic effect. Dissimilar to model $A$, where the pressure changes remain confined at depth in proximity of the inlet (Fig. $5 b$ ), in model $B$, the pressure change front proceeds toward the surface (Fig. 5e) engendering to an increase in the ground deformation rate. The maximum uplift and the higher deformation rate are, hence, attained for the model $B$, which reflects the ability of the hydrothermal system to respond faster to the injection of fluids due to higher permeability in the inner and transition zones.

473 For the model B, we have also investigated the effects on deformation generated by an increase in the rock permeability in the inner zone. Indeed, an increase in the gas output may be not only the consequence of an enhanced gas input but it may also reflect a temporal permeability increase in the gas pathway by rock fracturing. As the permeability value in the inner zone is doubled, the hydrothermal system is decompressed and subsidence in ground deformation is observed (Fig. 6). A further simulation is performed in which both the gas flux rate at the inlet and the permeability in the inner zone are increased. This simulation allows to investigate the effect of a potential positive feedback among enhanced gas input, pressurization of the hydrothermal system, rock fracturing and increase of permeability. In such a case, an uplift is still observed even if the amplitude is lower. Moreover, the deformation field is narrower and rapidly decays with distance. Indeed, the causeeffect relationship governing this feedback process may be more complex. Gas input may result in pressure increase, that leads to hydro-fracturing and permeability increase, that on its own results in fluid release, pressure decrease and closure of fracture. The simulation of this coupled mechanism could be more suitably described assuming a pressure-dependent permeability model (Rutqvist et al., 2002). 
492 To investigate failure conditions induced by the hydrothermal activity of Vulcano

493 Island during the simulated unrest, a stress-strain analysis is performed. The volcanic 494 edifice itself acts as a load on the upper crust and generates shear stress 495 components that greatly affect the volcano flank stability (Currenti and Williams, 496 2014). Therefore, in addition to the introduction of the pore pressure and thermo497 elastic stress, the model is subjected also to the gravity body force to become fully 498 compressed under its own weight (Reid, 2004). The stress state induced by the 499 topography loading is computed through the activation of gravitational body forces 500 (Bonaccorso et al., 2010; Cianetti et al., 2012; Currenti and Williams, 2014). This 501 procedure allows to reach an equilibrium state in the presence of gravity loading and 502 provides the stress distribution induced by the topography. A gradient in the stress 503 component $\sigma_{r}$ is achieved at the change of the topography curvature (Fig. 8a), 504 whereas $\sigma_{z}$ almost follows the topography shape (Fig. 8b). A shallow local 505 concentration in $\sigma_{\mathrm{rz}}$ is observed where an abrupt change of slope occurs at about $506700 \mathrm{~m}$ from the origin (Fig. 8c). The stress components generated by the pore 507 pressure and thermo-elastic contributions are used to compute the failure surfaces 508 expected at Vulcano Island at the end of the simulated unrest phase. On the basis of 509 the wide variabilities of mechanical parameters of Vulcano rock samples (Tommasi et 510 al., 2016), the yield failure function is computed for two different values of friction 511 angles: $20^{\circ}$ and $30^{\circ}$ (Figs. 9-10). The contour lines refer to the failure surfaces, which 512 are defined using Eq. 7 and computed for different values of the $\eta_{1}$ parameter 513 obtained for two values of the cohesion coefficient $\mathrm{c}=0.5 \mathrm{MPa}$ (white line) and $\mathrm{c}=1$ $514 \mathrm{MPa}$ (black line). Failure regions are located in the La Fossa cone and in the 515 steepest slope of the edifice. Both aerial and submarine failure surfaces develop 516 along the flank of the volcanic edifice (Figs. 9,10). The failure condition is strongly 517 dependent on the friction angle, whose reduction promotes the rocks to undergo 518 failure. The extension of the failure region is controlled by the cohesion coefficient 519 through the $\eta_{1}$ parameter. The lower the cohesion, the wider the area affected by 520 failure. It is worth noting that for lower cohesion coefficient the failure zone also 521 extends in the submarine portion of the volcanic complex. Similar results are 522 obtained both for model A and B. Slight enhancement in the extension of the failure 523 zone is observed for the model B due to the upward migration of the pore pressure 
changes. Indeed, since pressure and temperature changes are confined around the inlet region for model $A$ and mainly in the inner zone for model $B$, the stability of the volcano flanks, under the assumed model parameters, is not significantly influenced by the hydrothermal fluid circulation. The failure surfaces slightly differ from that computed under the only effect of gravitational loading (Fig.11).

\section{Discussion and Conclusions}

531 Stress-strain numerical analysis in volcanic areas is an increasingly interesting research topic, which may help in driving inferences on the internal state of a volcano edifice (Coco et al., 2014; Currenti,2014; Currenti and Williams, 2014; Schopa et al., 2011; Cianetti et al., 2012). Particularly, in this paper we proposed a geomechanical approach to evaluate the deformation and flank instability in volcanic hydrothermal systems with application to Vulcano Island. Numerical results support that thermal heating and pore pressure due to an increment in the inflow of volcanogenic fluids may generate temporarily pressurization of pore fluids, which induce ground deformation increasing in time as the injection of fluid is sustained. The comparison between the results obtained from model $A$ and $B$ indicates that the amplitudes, distribution and temporal evolution of the physical variables are strongly dependent on the model material assumptions. By investigating the numerical results, the model B seems to represent the more likely scenario since it is able to reproduce geophysical phenomena observed at Vulcano Island. In particular, in model B, the gas saturation distribution (Fig. 4f) covers a wide zone corresponding to the areas where diffuse emissions from the soil have been recorded all around the base of the volcanic La Fossa cone (Diliberto et al., 2002). With the present choice of initial conditions, injection rate and rock properties, based on a sound hydrothermal conceptual model, both horizontal and vertical deformation during unrest phase are within few centimeters. These findings are in agreement with geodetic observations from tilt (Cannata et al., 2011) and DInSAR measurements (Azzaro et al., 2013), which show no significant ground deformation during the most recent recorded anomalies in temperature, chemical composition and seismicity recorded during 2004-2006 (Alparone et al., 2010; Granieri et al., 2006). Continuous monitoring reveals that strong increases in fumaroles temperature and in superficial manifestations, with a remarkable enlargement of the exhalative area and a 
progressive increase in the $\mathrm{CO}_{2}$ emission rate, are generally observed when input of fluids of magmatic origin occurs (Granieri et al., 2006; Inguaggiato et al., 2012). The recurrence of these degassing events could be related to the progressive accumulation of volatile at the top of an accumulation zone, followed by a volatile release affecting the hydrothermal fluid budget and the pressurization in the surrounding media. Such anomalous degassing periods are accompanied by increases in the number and amplitude of volcano-seismic events at shallow depth $(<1-1.5 \mathrm{~km})$ under La Fossa cone (Alparone et al., 2010). Model B results highlight a pore pressure increase in a $0.5 \mathrm{~km}$ wide zone above the hydrothermal system at depths ranging between 1 and $0.25 \mathrm{~km}$ bsl, which may induce fracturing in the same area where micro-seismicity has been generally recorded. Supported by the lack of volcano-tectonic seismicity and significant deformation, our results agree with the hypothesis that micro-seismicity is likely related to pore pressure increase induced by the release of fluids from a deep magma zone rather to magma migration into the shallow hydrothermal system (Cannata et al., 2011). On the basis of the solved elastic effective stress field, the distributions of failure surface estimated using the Drucker-Prager criterion pinpoint locations that have an increasing exposure to flank failure. The numerical results evidence the strong dependence of the failure surface by the friction angle and cohesion. In the history no evidences for a large failure slope such as the one obtained for a friction angle of $20^{\circ}$ and a cohesion of $0.5 \mathrm{MPa}$ (Figs. 9-10) have been reported. The failure surfaces achieved for higher cohesion (1 $\mathrm{MPa}$ ) values are in general agreement with a landslide height evaluated by Achilli et al. (1998) for the 1988 event. The high sensitivity of the results on mechanical coefficients rises the need to conduct a more detailed characterization of rock in situ properties to better define the failure criterion parameters. Moreover, because of simplistic assumption on the mechanical rock properties due to the lack of measurements of in situ rock properties, the actual geometry of the failure surface could be likely more complex than the failure surfaces modeled here. However, our analysis provides for the first time an initial quantitative flank stability assessment induced by hydrothermal processes. For the investigated scenarios, the pore pressure and temperature change do not seem to affect significantly the edifice stability, which is mainly controlled by gravitational loading (Fig. 11) in agreement also with the results reported recently in Tommasi et al. (2016). Indeed, under the model assumption, hydrothermal activity is confined within 
591 the higher permeability areas near the inner zone and does not cause significant 592 stress perturbations along the volcano flank.

593 The findings of this study provide baseline information about the stability of the 594 volcano edifice, and lead to a reliable method for assessing the hazard associated 595 with crisis, or intensified activity, of the hydrothermal system fed by a source of hot 596 fluids. A more detailed numerical modeling of the proposed process in terms of 597 definition of fluid injection rates, model materials and parameters will benefit from a 598 multidisciplinary approach that enables to clarify cause-and-effect relationships and 599 to identify the critical controlling factors. Different distributions of rock properties may 600 greatly affect the results. Particularly, hydrothermal alteration may have locally 601 impacted permeability, porosity, thermal parameters, rock strength and mechanical 602 rock properties. Hydrothermally altered rocks seem to cover large zones in the 603 northern and southern flanks of La Fossa cone edifice, as evidenced by the 604 distribution of reduced magnetization areas inferred from 3D magnetic model (Napoli 605 and Currenti, 2016). The wide extension of this low magnetization regions is a 606 fingerprint of a more diffuse historical hydrothermal activity than in present days, 607 which may have drastically altered over time the hydrological and mechanical 608 properties of the rocks. Local changes in rock permeability may significantly alter the 609 migration pathway of hydrothermal fluids, which tend to easily flow upwards along 610 highest permeability zones. Moreover, the presence of local fractures may also affect 611 the shallow hydrothermal circulation influencing pressure and temperature changes 612 and, consequently, deformation and stress fields. Additionally, reduction in the friction 613 angle and in the cohesion depending on the grade of hydrothermal alteration may 614 locally enhance the extent of the region undergoing failure.

615 As a first attempt to integrate these elements in a unified framework, it raises several 616 issues that require further in depth study by experts in different fields to refine the 617 model and validate it with observations during crises period at Vulcano Island. We 618 are confident that the methodology presented here can contribute to improve the joint 619 interpretation of the geophysical, geochemical and seismological data recorded at 620 Vulcano and in similar volcanic environments. Consequently, this model-based 621 approach integrated with the monitoring observations may provide new hints 622 concerning fluid-rock interaction processes to allow for the specific characterization 623 and assessment of the volcano hydrothermal system. 
626 We thank the Editor L. Capra, A. Geyer and an anonymous referee for their 627 constructive reviews. The work of A. Coco was supported in part by the Santander 628 Research Scholarship Award Scheme 2017.

\section{References}

Achilli V, Baldi P, Baratin L, Bonin C, Ercolani E, Gandolfi S, Anzidei M, Riguzzi F (1998)

Digital photogrammetric survey on the island of Vulcano. Acta Vulcanol $10: 1-5$

Alparone S, Cannata A, Gambino S, Gresta S, Milluzzo V, Montalto P (2010) Time-space variation of the volcano seismic events at La Fossa (Vulcano, Aeolian Islands, Italy): new insights into seismic sources in a hydrothermal system. Bull Volcanol 72: 803-816

Apuani T, Corazzato C, Merri A Tibaldi A, (2013) Understanding Etna flank instability through numerical models, J Volc Geotherm Res 251: 112-126

Azzaro $\mathrm{R}$ et al(2015) Multi-disciplinary analysis of the relationships between tectonic structures and volcanic activity (Etna, Vulcano-Lipari system). Final Report of the Agreement INGV-DPC 2012-2021, Volcanological Programme 2012-2015, https://sites.google.com/site/progettivulcanologici/progetto_v3

Barberi F, Gandino A, Gioncada A, La Torre P, Sbrana A, Zenucchini C (1994) The deep structure of the Eolian arc (Filicudi-Panarea-Vulcano sector) in light of gravity, magnetic and volcanological data. J Volcanol Geotherm Res 61:189-206

Barde-Cabusson S, Finizola A, Revil A, Ricci T, Piscitelli S, Rizzo E, Angeletti B, Balasco M, Bennati L, Byrdina S, Carzaniga N, Crespy A, Di Gangi F, Morin J, Perrone A, Rossi M, Roulleau E, Suski B, Villeneuve N (2009) New geological insights and structural control on fluid circulation in La Fossa cone (Vulcano, Aeolian Islands, Italy). J Volcanol Geotherm Res 185: 231-245

Berrino G (2000) Combined gravimetry in the observation of volcanic processes in Italy. J Geodyn 30: 371-388

Blanco-Montenegro I, de Ritis R, Chiappini M (2007) Imaging and modelling the subsurface structure of volcanic calderas with high-resolution aeromagnetic data at Vulcano (Aeolian Islands, Italy). Bull Volcanol 69: 643-659. http://dx.doi.org/10.1007/ s00445006-0100-7

Bonaccorso A, Currenti G, Del Negro C, Boschi E (2010) Dike deflection modelling for inferring magma pressure and withdrawal, with application to Etna 2001 case. Earth Planet Sci Lett 293: 121-129. doi: 10.1016/j.epsl.2010.02.030 a magma chamber. Geophys J Int 103: 289-299 
Bonafede M (1991) Hot fluid migration: An efficient source of ground deformation: Application to the 1982- 1985 crisis at Campi Flerei, Italy. J Volcanol Geotherm Res 48: 187- 198

Brooks A, Corey AT (1964) Hydraulic properties of porous media. Colorado State 599 University Hydrology. Paper No. 3, Fort Collins, Colorado, USA

Cannata A, Diliberto S, Alparone S, Gambino S, Gresta S, Liotta M, Madonia P., Milluzzo V, Aliotta M, Montalto P (2011) Multiparametric approach in investigating volcano hydrothermal systems: the case study of Vulcano (Aeolian Islands, Italy). Pure Appl Geophys 169: 167-182

Cattin R, Doubre C, de Chabalier JB, King G, Vigny C, Avouac JP, Ruegg JC (2005) Numerical modelling of quaternary deformation and post-rifting displacement in the Asal-Ghoubbet rift (Djibouti, Africa). Earth Planet Sci Lett 239: 352-367

Chen W F (1982) Plasticity in reinforced concrete. McGraw-Hill, New York, N.Y.

Chiarabba C, Pino NA, Ventura G, Vilardo G (2004) Structural features of the shallow plumbing system of Vulcano Island Italy. Bull Volcanol 66: 477-484

Chiodini G, Cioni R, Falsaperla S, Guidi M, Marini L, Montalto A (1992) Geochemical and seismological investigations at Vulcano (Aeolian islands) during 1978-1989. J Geophys Res 97: 11025-11032

Chiodini G, F Frondini, B Raco (1996) Diffuse emission of CO2 from the Fossa crater, Vulcano Island (Italy). Bull Volcanol 58: 41-50

Cianetti S, Giunchi C, Casarotti E (2012) Volcanic deformation and flank instability due to magmatic sources and frictional rheology: the case of Mount Etna. Geophys J Int. doi: 10.1111/j.1365-246X.2012.05689.x

Coco A, Currenti G, Del Negro C, Russo G (2014) A second order finite-difference ghostpoint method for elasticity problems on unbounded domains with applications to volcanology. Commun. Comput. Phys., 16, 983-1009. doi: 10.4208/cicp.210713.010414

Coco A, Gottsmann J, Whitaker F, Rust A, Currenti G, Jasim A, Bunney S (2016) Numerical models for ground deformation and gravity changes during volcanic unrest: simulating the hydrothermal system dynamics of a restless caldera. Solid Earth 7: 557-577. doi:10.5194/se-7-557-2016

Comsol Multiphysics 4.3 (2012), Comsol Ab, 1356 pp, Stockholm, Sweden

Currenti G (2014) Numerical Evidences Enabling To Reconcile Gravity And Height Changes In Volcanic Areas. Geophysical Journal International. doi 10.1093/Gji/Ggt507

Currenti G, Williams CA (2014) Numerical modeling of deformation and stress fields around a magma chamber: constraints on failure conditions and rheology. Phys Earth Planet Int 226: 14-27. doi:10.1016/j.pepi.2013.11.003 
De Astis G, Ventura G, Vilardo G (2003) Geodynamic significance of the Aeolian volcanism (southern Tyrrhenian Sea, Italy) in light of structural, seismological and geochemical data. Tectonics 22 4. DOI 10.1029/2003TC001506

De Astis G, Lucchi F, Dellino P, La Volpe L, Tranne CA, Frezzotti ML, Peccerillo A (2013) Geology, volcanic history and petrology of Vulcano (central Aeolian archipelago). Geol Soc Lond Mem 37: 281-349. http://dx.doi.org/10.1144/M37.11

De Natale G, Pingue F, Allard P, Zollo A (1991) Geophysical and geochemical modelling of the 1982-1984 unrest phenomena at Campi Flegrei caldera (southern Italy). J Volcanol Geotherm Res 48: 199-222

De Natale G, Troise C, Pingue F. (2001) A mechanical fluid- dynamical model for ground movements at Campi Flegrei caldera. J Geodyn 32: 487-517. doi:10.1016/S02643707(01)00045-X

De Ritis R, Blanco-Montenegro I, Ventura G, Chiappini M (2005) Aeromagnetic data provide new insights on the tectonics and volcanism of Vulcano island and offshore areas (southern Tyrrhenian Sea, Italy). Geophys Res Lett 32 (L15305). doi 10.1029/2005GL023465

Diliberto IS, Gurrieri S, Valenza M (2002) Relationships between diffuse CO2 emissions and volcanic activity on the island of Vulcano (Aeolian Islands, Italy) during the period 19841994. Bull Volcanol 64: 219-228

Elsworth D, Voigth B (1996) Evaluation of volcano flank instability triggered by dyke intrusion. In: MCGuire, W. J. Jones, A.P. \& Neuberg J (eds). Volcano instability on the Earth and Other Planets. Special Publications of the Geological Society of London, 110: 45-54

Elsworth D, Day S (1999) Flank collapse triggered by intrusion: the Canarian and Cape Verde Archipelagoes. J Volcanol Geoth Res 94(1-4): 323-340

Faraone D, Silvano A, Verdiani G (1986) The monzogabbroic intrusion in the island of Vulcano, Aeolian archipelago, Italy. Bull Volcanol 48:299-307

Federico C, Capasso G, Paonita A, Favara R (2010) Effects of steam-heating processes on a stratified volcanic aquifer: stable isotopes and dissolved gases in thermal waters of Vulcano Island (Aeolian archipelago). J Volcanol Geotherm Res 192: 178-190. http://dx.doi.org/10.1016/j.jvolgeores.2010.02.020

Fung Y (1965) Foundations of solid mechanics. Prentice-Hall, Englewood Cliffs

Gioncada, A., Sbrana, A., (1991). "La Fossa caldera", Vulcano: inferences from deep drillings. Acta Vulcanol 1: 115-125

Got JL, Peltier A, Staudacher T, Kowalski P, an Boissier P (2013), Edifice strength and magma transfer modulation at Piton de la Fournaise volcano. J Geophys Res Solid Earth 118. doi:10.1002/jgrb.50350 
Granieri D, Carapezza M L, Chiodini G, Avino R, Caliro S, Ranaldi M, Ricci T, Tarchini L (2006), Correlated increase in CO2 fumarolic content and diffuse emission from La Fossa crater (Vulcano, Italy): Evidence of volcanic unrest or increasing gas release from a stationary deep magma body? Geophys Res Lett 33: L13316, doi:10.1029/2006GL026460

Hayba D, Ingebritsen S (1994) Multiphase Groundwater Flow Near Cooling Plutons. J Geophys Res 102: 12,235 - 12,252

Hurwitz S, Christiansen L B, Hsieh P A (2007) Hydrothermal fluid flow and deformation in large calderas: Inferences from numerical simulations. J Geophys Res 112, B02206, doi:10.1029/2006JB004689.

Hutnak M, Hurwitz S, Ingebritsen SE, Hsieh PA (2009) Numerical models of caldera deformation: Effects of multiphase and multicomponent hydrothermal fluid flow. $J$ Geophys Res 114: B04411, doi:10.1029/2008JB006151

lacobucci F, Incoronato A, Rapolla A, Scarascia S (1977) Basement structural trends in the volcanic islands of Vulcano, Lipari, and Salina (Aeolian Islands, Southern Tyrrhenian Sea) computed by aeromagnetic and gravimetric data. Boll Geofis Teor Appl 20:73-74, $49-61$

Inguaggiato S, Mazot A, Diliberto IS, Inguaggiato C, Madonia P, Rouwet D, Vita F (2012) Total CO2 output from Vulcano island (Aeolian Islands, Italy). Geochem Geophys Geosyst 13:Q02012, doi:10.1029/2011GC003920

Iverson R.M, Reid ME (1992) Gravity driven groundwater flow and slope failure potential: 1: Elastic effective-stress model. Water Resources Research 28, 925-938

Iverson RM (1995) Can magma-injection and groundwater forces cause massive landslides on Hawaiian volcanoes? JVolcanol Geother Res 66: 295-308

Jaeger J, Cook N, Zimmerman R (2007) Fundamentals of Rock Mechanics (4th Edition). Blackwell Publishing, Oxford

Kearey P, Brooks M (1991) An introduction to geophysical exploration. Second edition. Blackwell Scientific Publications, Oxford, 254 pp

Liu L, Zoback M D (1992) The Effect of Topography on the State of Stress in the Crust: Application to the Site of the Cajon Pass Scientific Drilling Project. J Geophys Res.97(B4): 5095-5108, doi:10.1029/91JB01355

Liu HY, Kou SQ, Lindqvist PA, Tang CA (2004) Numerical studies on the failure process and $149-174$

Martí J, Geyer A (2009) Central vs flank eruptions at Teide-Pico Viejo twin stratovolcanoes (Tenerife, Canary Islands). J Volcanol Geotherm Res 181: 47-60 
Mazzini A, Nermoen A, Krotkiewski M, Podladchikov Y, Planke S, Svensen H (2009) Strikeslip faulting as a trigger mechanism for overpressure release through piercement structures. Implications for the Lusi mud volcano, Indonesia. Marine and Petroleum Geology. doi:10.1016/j.marpetgeo.2009.03.001

McGuire WJ (1996) Volcano instability: a review of contemporary themes. Geol Soc London Spec Pub 110:1-23

Muller, J.R., Ito, G. and Martel, S.J., 2001. Effects of volcano loading on dike propagation in an eastic half-space. Journal of Geophysical Research, 106(B6): 11101-11113.

Napoli R, Currenti G (2016), Reconstructing the Vulcano Island evolution from 3D modeling of magnetic signatures. J Volcanol Geother Res 320: 40 - 49. doi:10.1016/j.jvolgeores.2016.04.011

Okubo A, Kanda W (2010) Numerical simulation of piezomagnetic changes associated with hydrothermal pressurization. Geophys J Int 181: 1343-1361

Orsi G, Petrazzuoli SM, Wohletz K (1999) Mechanical and thermo- fluid behaviour during unrest at the Campi Flegri caldera (Italy). J Volcanol Geotherm Res 91: 453-470. doi:10.1016/S0377-0273(99) 00051-7

Pan E, Amadei B, Savage WZ (1995) Gravitational and Tectonic Stresses in Anisotropic Rock with Irregular Topography. Int J Rock Mech Min Sci.\& Geomech Abstr 32, 3: 201 214

Paonita A, Federico C, Bonfanti P, Capasso G, Inguaggiato S, Italiano F, Madonia P, Pecoraino G, Sortino F (2013) The episodic and abrupt geochemical changes at La Fossa fumaroles (Vulcano Island, Italy) and related constraints on the dynamics, structure, and compositions of the magmatic system. Geochimica et Cosmochimica Acta 120: 158-178. doi: 10.1016/j.gca.2013.06.015

Pinel V, Jaupart C (2004) Magma storage and horizontal dyke injection beneath a volcanic edifice. Earth and Planetary Science Letters 221: 245-262

Pruess K, Oldenburg C, Moridis G (1999) TOUGH2 User's Guide, Version 2.0, Lawrence Berkeley Natl Lab, Berkeley, Ca, Usa

Ranalli G, (1995) Rheology of the Earth. pp. 413, Chapman and Hall, London

Rasà R, Villari L (1991) Geomorphological and morpho-structural investigations on the Fossa cone (Vulcano, Aeolian Islands):a first outline. Acta Vulcanol 1 :127-133

Reid ME (2004) Massive collapse of volcano edifices triggered by hydrothermal pressurization. Geology 32: 373-376

Revil A, Finizola A, Piscitelli S, Rizzo E, Ricci T, Crespy A, Angeletti B, Balasco M, Barde Cabusson S, Bennati L, Bole've A, Byrdina S, Carzaniga N, Di Gangi F, Morin J, Perrone A, Rossi M, Roulleau E, Suski B (2008) Inner structure of La Fossa di Vulcano (Vulcano Island, southern Tyrrhenian Sea, Italy) revealed by high-resolution electric 
804

805

806

807

808

809

810

811

812

813

814

815

816

817

818

819

820

821

822

823

824

825

826

827

828

829

830

831

832

833

834

835

836

837

838

839

resistivity tomography coupled with selfpotential, temperature, and $\mathrm{CO} 2$ diffuse degassing measurements. J Geophys Res 113 B07207-1 21. doi: 10.1029/2007JB005394

Rinaldi A, Todesco Bonafede M, Vandemeulebrouck MJ, Revil A (2011) Electrical conductivity, ground displacement, gravity changes, and gas flow at Solfatara crater (Campi Flegrei caldera, Italy): results from numerical modeling. J VolcanolGeother Res 207:93-105

Rinaldi A, Todesco M, Bonafede M (2010) Hydrothermal instability and ground displacement at the Campi Flegrei caldera. Physics of the Earth and Planetary Interiors 178: 155 161

Romagnoli C, Casalbore D, Bosman A, Braga R, Chiocci FL (2013) Submarine structure of Vulcano volcano (Aeolian Islands) revealed by high-resolution bathymetry and seismoacoustic data. Marine Geology 338: 30-45, doi: 10.1016/j.margeo.2012.12.002

Roeloffs EA (1988) Fault stability changes induced beneath a reservoir with cyclic variations in water level J Geophys Res, 93 B3: 2107-2124

Rutqvist J, Wu YS, Tsang CF, Bodvarsson GA (2002) Modeling approach for analysis of coupled multiphase fluid flow, heat transfer, and deformation in fractured porous rock. International Journal of Rock Mechanics and Mining Sciences 39: 429-442

Schöpa A, Pantaleo M, Walter TR (2011) Scale-dependent location of hydrothermal vents: Stress field models and infrared field observations on the Fossa Cone, Vulcano Island, Italy, J Volcanol Geotherml Res 203: 133-145

Tinti S, Bortolucci E, Armigliato A (1999) Numerical simulation of the landslide-induced tsunami of 1988 on Vulcano Island, Italy. Bull Volcanol 61:121-137

Todesco M (1997) Origin of fumarolic fluids at Vulcano (Italy). Insights from isotope data and numerical modeling of hydrothermal circulation. J Volcanol Geotherm Res 79: 63-85. doi:10.1016/S0377-0273(97)00019-X

Todesco M, Chiodini G, Macedonio G (2003) Monitoring and modelling hydrothermal fluid emission at La Solfatara (Phlegrean Fields, Italy). An interdisciplinary approach to the study of diffuse degassing. J Volcanol Geotherm Res 125: 57-79. doi:10.1016/S03770273(03)00089-1

Todesco M, Rinaldi AP, Bonafede M (2010) Modeling of unrest signals in heterogeneous hydrothermal systems. J Geophys Res 115 B09213. doi:10.1029/2010JB007474

Tommasi P, Rotonda T, Verrucci L, Graziani A, Bolidini D (2016) Geotechnical analysis of instability phenomena at active colcanoes: Two cases histories in Italy in Landslides and Engineered slopes. Experience, theory and Practices, ed. Aversa et al Associazione Geotecnica Italiana, Rome, Italy 
840 Troiano A, Di Giuseppe M, Petrillo Z, Troise C, De Natale G (2011) Ground deformation at 841 calderas driven by fluid injection: modelling unrest episodes at Campi Flegrei (Italy).

$842 \quad$ Geophysical Journal International 187: 833 - 847

843 Ventura G, Vilardo G, Milano G, Pino NA (1999) Relationships among crustal structure, 844 Volcanism and strike-slip tectonics in the Lipari-Vulcano volcanic complex (Aeolian 845 Islands, Southern Tyrrhenian Sea, Italy). Physics Earth Planet Int 116: 31-52

846 Voight B, Elsworth D (1997) Failure of volcano slopes. Geotechnique 47: 1-31

847 Voight B, Glicken H, Janda RJ, Douglas PM (1981) Catastrophic rockslide avalanche of May 848 18. In: Lipman PW, Mullineux DR (eds) The 1980 eruption of Mount St. Helens. U.S. 849 Geol. Survey Prof. Paper, 1250, 347-377

850 Zang A, Stephansson O (2010) Stress Field of the Earth's Crust. Springer, Berlin

851 Zienkiewicz OC, Emson C, Bettess P (1983) A novel boundary infinite element. Int J Numer $852 \quad$ Methods Eng 19: 393-404

853 


\section{Table Captions}

855

856 Table 1 - List of symbols in SI units.

857

858 Table 2 - Hydrological properties assigned to the model material.

859

860 Table 3 - Mechanical elastic parameter

861

862 
865 Figure 1 - Simplified geological map of the Vulcano Island. Legend: 1) alluvium and beach 866 deposits; 2) Vulcanello pyroclastics: 3) Vulcanello lava flows; 4) Fossa cone pyroclastics; 5) 867 Fossa cone lava flows; 6) Lentia domes and lava flows; 7) hyaloclastites and pillow lava; 8) 868 lava flows and minor pyroclastics; 9) South Vulcano lavas and scorias; 10) drilling location. 869 The profile crossing the 1988 landslide (black line) to define the topography of the axisymmetric model is also reported.

871

872 Figure 2 - Representation of the fluid flow (top) and mechanical (bottom) computational 873 domains. The model is axis symmetric. The mechanical domain is extended to use infinite 874 elements (green area). The actual grid and mesh are much finer than resolution shown in the 875 figure.

876

877 Figure 3 - A simplified scheme of the complex geological structure of the volcanic edifice for the Models A (top) and B (bottom) based on the stratigraphy of the VP1 deep borehole reported on the left (after Blanco-Montenegro et al., 2007). The model domain is composed

880 of five different regions: Layer 1 (L1); Layer 2 (L2); Transition zone for L1 (T1); Transition zone for L2 (T2); Inner zone (IZ).

882

883 Figure 4 - Temperature, pressure and saturation distributions used as initial conditions. A 884 quasi-steady state solution is achieved by simulating a thousand years of continuous 885 injection of $1300 \mathrm{t} /$ day of $\mathrm{H}_{2} \mathrm{O}$ and $450 \mathrm{t} /$ day of $\mathrm{CO}_{2}$ at a temperature of $350{ }^{\circ} \mathrm{C}$ for model $\mathrm{A}$ 886 (top) and model B (bottom).

887

888 Figure 5 - Changes in temperature and pressure with respect to initial conditions after 1 889 year of unrest simulated increasing the flux rate to $2000 \mathrm{t} /$ day for the water and to $1000 \mathrm{t} /$ day 890 for the carbon dioxide content for model A (top) and model B (bottom). The gas saturation 891 distributions are also shown.

892

893 Figure 6 - Radial distributions of horizontal (top) and vertical (bottom) displacements for 894 model A (red lines) and model B (blue lines) after 1 year of unrest simulated increasing the 895 flux rate to 2000 t/day for the water and to 1000 t/day for the carbon dioxide content. For 896 model B the displacements obtained for an increase of the permeability in the inner zone 897 (black line) and increases both in flux rate and permeability (green line) are also shown. 
899 Figure 7 - Temporal evolution of vertical ground displacement for model A (red lines) and

900 model B (blue lines) at the ground surface in the origin point $(r=0)$ during a 1-year of unrest.

901

902 Figure 8 - Stress components under gravitational topographic loading.

903

904 Figure 9 - Volcanic edifice failure estimated after a 1-year long unrest by simulating an 905 increase in the injection rate of a mixture of water and carbon dioxide for model $\mathrm{A}$. The failure 906 criterion is computed for a cohesion of $0.5 \mathrm{MPa}$ and friction angles of $20^{\circ}$ (top) and $30^{\circ}$ 907 (bottom). The contour lines define the failure surfaces for values of cohesion coefficient of $908 \quad 0.5$ (black line) and $1 \mathrm{MPa}$ (white line).

909

910 Figure 10 - Volcanic edifice failure estimated after a 1-year long unrest by simulating an 911 increase in the injection rate of a mixture of water and carbon dioxide for model $\mathrm{B}$. The failure 912 criterion is computed for a cohesion of $0.5 \mathrm{MPa}$ and friction angles of $20^{\circ}$ (top) and $30^{\circ}$ 913 (bottom). The contour lines define the failure surfaces for values of cohesion coefficient of $914 \quad 0.5 \mathrm{MPa}$ (black line) and $1 \mathrm{MPa}$ (white line).

915

916 Figure 11 - Volcanic edifice failure controlled by only gravitational loading. The failure 917 criterion is computed for a cohesion of $0.5 \mathrm{MPa}$ and friction angles of $20^{\circ}$. The contour lines 918 define the failure surfaces for values of cohesion coefficient of $0.5 \mathrm{MPa}$ (black line) and 1 919 MPa (white line).

920 